\title{
A Discussion of Reification in the Human-Technology Relationship through an Examination of Cyborg
}

\author{
Rui Zhou \\ The Affiliated High School of South China Normal University, Guangzhou, Guangdong 510631, China \\ zhourui040205@icloud.com
}

\begin{abstract}
As the modern technology plays a more ubiquitous role than ever in society, it becomes crucial for us to understand humans in relation to technology. To achieve this goal, this study raises the question of whether the human subject is reified in the cyborg (a fictional form of life that combines technology and the human body). The study compares and analyzes different arguments on technology mainly from Heidegger, Stiegler, and Coeckelbergh, and extends them to the issue of cyborgs. By applying the subjective figure of technology in science fiction, this study proposes to take a position neglected by studies previously mentioned, which is the potential subjectivity of technology itself. Through this discussion on cyborgs, it is hoped that the problem of human-technology relation, an issue derived immediately from the core of modern society, can be understood more comprehensively.
\end{abstract}

Keywords: technology, cyborg, reification, science fiction, Heidegger, Stiegler

\section{INTRODUCTION}

Entering the twenty-first century, human beings and modern technology are so tightly intertwined together that it is almost impossible to separate them into two individual parts, and cyborg - the hybrid or "coming together" of the organic human body and inorganic technology that used to be an element existing only in the fantasy of science fiction - now seems to be more and more relevant to the society. The concept of the cyborg is not without criticism: a major concern of cyborgs is its possible negative influence on human subjectivity, as many may worry that cyborgs will degrade human beings into pure mechanical objects. The concept related to this is reification, a Marxist-Lukácsian term that refers to the process in which the human subject is reduced to a passive, calculable object and loses its subjectivity, which can take the form of rationalization as people are reduced to abstract numbers and inserted into a mechanical system [1]. The question here, therefore, is whether the cyborg will necessarily reify the human subject. To answer this question, this research will summarize and analyze influential works on technology from various authors, extend those arguments to the realm of cyborgs, and propose a position commonly neglected by those arguments through an analysis of science fiction. By answering the question closely related to humantechnical relations, this research aims to more thoroughly understand the technology and obtain a correct attitude toward human's relationship with it.

\section{LITERATURE REVIEW}

Questions concerning technology has been a longlasting debate in the academy; within that debate, there is a noticeable tradition in phenomenological approach, including but not limited to Heidegger, Stiegler, Verbeek, Dreyfus, and Coeckelbergh.

For Heidegger, the essence of modern technology is never an innocent instrument, but instead a way to reveal the truth of being; this perspective taken one step further, the merging of man and technology will not be a neutral process either. In The question concerning technology, Heidegger states that technology "is based on modern physics as an exact science" [2]. For him, the essence of this exact science, what he calls "research", is that it is mathematical: it assumes the calculability of its object so that everything can be calculated in advance and reduced to pure numbers set in place, for only in this way is an object considered being [3]. And it is not simply that the basis of technology allows everything to be calculated exactly, but that the exactitude of it requires and demands everything to be calculated exactly. The calculability and exactitude are therefore the fundamental parts of the revealing process of technology. And so under the examination and practice of technology, 
one can be, or be recognized as being, only if one becomes an object for calculation.

However, when a human is thrown into the revelation of exactitude, it is no longer a concrete and active subject, but rather some passive, replaceable, and quantified numbers. Thus by extending Heidegger's reasoning, it can be argued that human beings, when combining with modern technology, will become the calculative and mechanical object, set in place as a standing-reserve (Bestand); "living thing can indeed also be grasped as a spatiotemporal magnitude of motion, but then it is no longer apprehended as living" [3]. Here, it can be seen that from a Heideggerian perspective, cyborgs will reify human subjects, because, through the hybrid with modern technology, human beings are reduced to mechanical objects prepared for calculation. What is different here, though, is that this reification cannot be described as "a loss of subjectivity", for Heidegger himself opposes the traditional subject-object division.

Yet, this Heideggerian approach is somewhat too intrigued by the poiesis of techne from ancient time, thus does not grasp fully the nature of technology, which makes the argument appears nostalgic to some degree. To avoid the nostalgic interpretation, it is necessary to develop a new approach to criticize this overly poetic view of technology. One convincing objection is made by Stiegler, who is much influenced by Heidegger on the definition of technology. He argues that Heidegger assumes a clear distinction between technology and the development of humanity, while the truth is otherwise. Although Stiegler agrees with Heidegger in seeing technology as a way of revealing the truth of being, he further points out that Heidegger has been missing a crucial fact: humanity itself is an invention of the technical. The theoretical origin of this divergence is that different from Stiegler, Heidegger does not realize how ubiquitously technology has shaped Dasein, and that Stiegler would rather put technology in the center of civilization as the ancient Greeks did [4]. According to Stiegler, technology has always been shaping human beings as well as the whole civilization, from the primitive tools that pushed forward the evolution of the human cerebral cortex to more developed tools that shaped and are still shaping the language system. Analogous to the famous statement from Engels claiming that "labour created man himself" [5], Stiegler argues that "technical inventing the human, the human inventing the technical" [6]. Instead of the traditional interpretation where the human simply invents the technical, he claims that the two sides invent each other. Viewing man as a dynamic process of becoming, Stiegler observes that in the human-technical relation, each side interacts with the other to form a subject-object relation that evolves synchronously. Technology is already deeply rooted in the formation of humanity, and the historicity of humans is in nature the interaction between the human and the technical.
Similar to Stiegler, Haraway proposes that there "is no fundamental, ontological separation in our formal knowledge of machine and organism, of technical and organic" [7]. Technology is not just the historicity, but also the ontology and politic of human beings. This argument is followed by Verbeek, who attempts to develop the hybrid intentionality of cyborgs in which the human and the technical merge together to form a new, single experiencing entity rather than simply embody within each other [8]. As such, technology is itself an irreplaceable part of the human subject. In this sense, cyborg, which already becomes reality instead of staying as an imagination, does not reify the human subject but rather produces and maintains the subjectivity, for the human subject itself is already a cyborg.

One deficiency with the hybrid argument, according to Coeckelbergh's perspective, is that it ignores the potentially alienating effect. Different from the two perspectives above, Coeckelbergh's proposal is in some sense the synthesis of them. He neither follows Heidegger's monolithic view on technology nor claims that man is already technological as Stiegler does; instead, he tries to transcendentally interpret man and technology as merging on an ontological level and separated on an ontic level. What this means is that man is not technology, but the being-in-the-world of man depends on technology. Following the ethics from Dreyfus and Borgmann, in which technology is a matter of doing, engaging, and knowing-how [9,10], Coeckelbergh argues that technology promotes an active way for man, or the subject, to engage more fully with the surrounding world. And because being-in-the-world persists only through doing-in-the-world, the being of man is then tightly bounded with technology on an ontological level. The theoretical motive of this synthesized interpretation, according to Coeckelbergh, is to pay attention to the objectification problem, which the technical-central hybrid approach neglects, and at the same time avoid the nostalgia issue from the Heideggerian approach [11].

Extending Coeckelbergh's argument to the realm of cyborg, the answer to the question of reification is not quite straightforward. Unlike human-technical hybrid argument, human beings, in Coeckelbergh's perspective, are not machines, for they are never the same on an ontic level, and so cyborg - the hybrid of machine and organism-can become the source of reification. However, if the embedding of technology into the human body is for better promoting man to engage with the surrounding, then it becomes a reconciliation of the subject and the object, and a way for man to be in the world ontologically, in which the subjectivity of human being is reserved and the reification is avoided.

To summarize, the existing debate includes Heidegger's argument that technology as a way of revealing the truth, since it is based on the calculability of 
exact science, makes cyborg a kind of reification through wrongly assuming the exactitude of living being and applying calculative rationality that reduces man to pure numbers; Stiegler's argument that the human is already the technical, that the technical not only reveals the truth of being, but also invents human, and that cyborg does not cause reification of man because man is already cyborg; and Coeckelbergh's synthesis that technology should be a way for man to act in the world and that human is not technical on an ontic level, so cyborg will cause reification if it is not to interact with the surrounding.

\section{METHODOLOGY}

The literature review has introduced the direct relation between cyborgs and the theories of Heidegger, Stiegler, Haraway, and Coeckelbergh. To obtain a more comprehensive understanding of cyborg relation in the modern context, it is necessary to develop an analysis by putting the issue under complete frameworks, as well as compare those theories of human-technical relation and apply them to the combination and coexistence of human and technology.

To ask the question concerning reification, this research will investigate the role of reification, which is developed by Lukács, under the theories of Heidegger, Stiegler, Haraway, and Coeckelbergh through their theoretical origins and basic logic respectively.

By analyzing the role of technology in some influential science fictional works, the research will attempt to raise awareness of modern technology's possibility of sublating the reification imposed on people and generating a new, hybrid subjective consciousness through cyborgs.

\section{RESEARCH STUDY AND ANALYSIS}

\subsection{Concealing and Enframing}

For Heidegger, what needs to be paid with much attention here is that even though the technology is the Zeitgeist - that is, the spirit of the era- of our modern society and the core component of modernity, the dominance of technology as a way to reveal beings will still turn out to be a disaster for humanity. In Heidegger's eyes, science, the basis of modern technology, is a process of machination that assumes everything can be calculated and rationalized; thus, from the viewpoint of modern technology, people see beings not as themselves, but rather as a World Picture (Weltbild), the representations of beings after calculation. The truth of beings is translated into simply a set of numbers and magnitudes of motion, while the rest part of the beings is overlooked by and hidden from human cognition. Hence, beings are concealed by modern technology, despite the fact that the latter is a way of revealing beings and making them visible. To avoid this, Heidegger suggests reflecting on modern technology, to realize and be open to the fact that there are more ways of understanding beings other than science and technology instead of viewing technology as the only revelation [12].

Aside from the concealing aspect, Heidegger also argues that modern technology — unlike the ancient way of living in which peasants nourished the earth to let crops grow out of it - sees earth not as the earth itself, but as a resource and storage of crops and oil ready to be drawn out and utilized. Through such enframing (Gestell), all beings are to be embedded and fixed in the grand, allencompassing apparatus of science and technology. It challenges beings to be converted into resources and utilized, therefore accelerating the society to an extent that humans forget their origin. "The ordering belonging to Enframing sets itself above the thing [...]Enframing disguises even this, its disguising, just as the forgetting of something forgets itself" [12].

Under such argument, cyborg as the application of technology on humans is both revealing and concealing. By putting electronic chips into the brain or changing one's arms to artificial ones, technology reveals that the way human beings work is technical, thus mechanical and mathematical. On the other hand, however, it also conceals the rest of being. During such a process, only the quantified, calculative, and mechanized aspect of being can be expressed, while the other aspect of being as a living thing fails to manifest itself. Moreover, under the dominance of modern technology, human beings are seen as resources, which can be demonstrated from the phrase "human resource". This indicates that human beings, just like all other beings in modern society, have become a standing-reserve under the enframing, therefore challenged and urged to be "drawn out" and utilized under the technological apparatus. In the form of the cyborg, human beings will be more deeply embedded into such technological apparatus because of the structural similarity between them; consequently, the human may become a homogenized and identical part of it and lose all the individuality.

From the consequences of cyborg shown above, it may then be argued that the cyborg can indeed reify human beings, for it reduces humans to the mere magnitude of motion, while the aspect of human as a living being is concealed; what's more, the enframing demands and challenges even Dasein, or human, to become a resource utilized by and inserted into the technological apparatus as a whole. Under such circumstance in which humanity has not reflected on technology nor seen other possibilities, the former will be dominated by the latter, which fits the main characteristic of reification: human being loses the human characteristic, then is reduced to calculable numbers and a homogeneous part of the machine. However, it is critical here to remember that this reification does not 
involve the traditional distinction between subject and object, nor does it emphasize subjectivity; rather, it should be viewed in a Heideggerian perspective - that is, to view this as the intensive relationship between Dasein and being that is concealed by modern technology, and thus Dasein forgets to ask the question of being.

\subsection{Human as the invention of technology}

Inheriting a major part of Heidegger's argument, Stiegler agrees that technology is never a neutral tool, that it is a specific way in which Dasein reveals beings, and that "Technicization through calculation drives Western knowledge down a path that leads to a forgetting of its origin, which is also a forgetting of its truth" [6]. However, though largely influenced by Heidegger, Stiegler himself takes an approach very much different from that of Heidegger in a more ambivalent way.

To Stiegler, the previous philosophers all overlook a fact crucial to the discussion of technology. He states, in a cyborg's manner, that human is essentially technical, that the role technology plays in human civilization is more critical than believed, and that technology is the core in shaping Dasein. To demonstrate this, he traces back to the ancient Greek mythology of Epimetheus and Prometheus. In the myth, Epimetheus, who was in charge of giving all creatures their gifts, forgot to attribute any specific feature to humans; in order to compensate for this, Prometheus stole the fire and gave it to humans along with humans' ignorance of the future.

From such mythology, Stiegler points out that the original forgetting of Epimetheus leads to human's absence of natural quality at birth, while the fire from Prometheus, which is a metaphor for technology, becomes the exteriorized essence of the human being instead. Unlike Heidegger, who sees technology as becoming dominant only in the last few centuries, Stiegler states that technology is not only the essence of the modern epoch but also the essence of all human civilization throughout history, for technology has shaped Dasein as a prosthetic organ of human. In an anthropological sense, he argues that standing up of the human freed the forelimb, allowing the human to utilize tools, which he views as the primitive form of technology. Technology motivated apes to become human, changing not only the way human's fingers are arranged, but also exerted a profound influence on human's brain structure as well as language system; without the technology of spears, hoes, paper, or computers, we would never be the human that we are today, nor speak in the same way we do. Technical is human historicity [6].

It can thus be argued that because the essence of human is technical, and because human is the creation of technology, human has always been a form of cyborg from the long combination of the two. Haraway and
Verbeek are on the same path, pointing out either that technology is the politic and ontology of human, or that human and technology become a new phenomenological entity with its innovative intentionality $[7,8]$. The potential argument is that since human is already cyborg and technology is the essence of human, becoming more deeply combined with technology will not lead to a 'loss' of humanity, not to mention reification.

However, what should not be forgotten is that, just like Haraway and other philosophers, Stiegler also points out how modern technology keeps accelerating its pace and leaves Dasein behind, concealing the problem of the "proletarianization"- $\mathrm{a}$ form of reification that deprives the knowledge of "how to do" and individual thinkingof human [13]. Under Stiegler's approach, the effect of technology is subtle: it is both the medicine and the poison. On the one hand, technology compensates for humans' lack of nature by being an exterior prosthetic organ, through which humans can develop and return to themselves. On the other hand, the ever-accelerating pace of modern technology proletarianizes humans through the mass production of digital industry as well as the algorithmic governmentality of digital capitalism [14]. Stiegler argues that modern technology separates Dasein from the direct experience and interaction with labor's objects. Moreover, through modern technology in the cultural industry, people's activities are calculated by algorithms, their consumption becoming repetitive and mechanical, in which the human mind loses its uniqueness and imagination, thus becomes proletarianized

From this approach, one can argue then that although human is already deeply intertwined with the technical, reification can still arise from technology's proletarianization of human and the algorithmic governmentality upon people's way of living.

\subsection{Being-in-world and Skilled Activities}

Another phenomenological tradition, which has not been recognized enough during the previous discussion on technology, is the way Dasein interacts with the surrounding world. Attempting to develop the ethics of skill, Dreyfus claims that being-in-world always involves doing-in-world, and thus the basis of Dasein is the interaction with the surrounding world, which is only possible through skilled activity [15]. Thus the ontology of humans becomes the active engagement with the objects, in the process of which the subject and the object are not separated as in Cartesian tradition, but rather acting together coherently, and subject to object under interaction is just like the lung to air when breathing: they are not one, but they are tightly related together by acting harmoniously [11].

Applying this to technology, Dreyfus argues that ethical technology should be a way for humans to 
bring further engagement with the surrounding, as the way craftsman would hammer a nail into the wood. Otherwise, we will lose our basic ontology and become alienated from the world. However, this demand for engagement is not fulfilled in modern technology; on the contrary, modern technology has, as Dreyfus sees it, deprived our ability to have skilled activities, meaning that people cannot be directly involved in the process in a personal way that allows the subject to ontologically combine with the object [15]. For example, when a person is typing codes on a computer, that person is not engaging with the program produced because the communication between subject and object are, in this case, mediated and even isolated by the computer, not to mention the fact that the object itself cannot be directly engaged with. This implies that through the mediation of modern technology, human is alienated from the surrounding and deprived of skilled activities.

Dreyfus, along with others, also advocates for a more poietic way of living. Tracing back to what Heidegger calls "poiesis" [2], he embraces the nurturing manner, in which just like how farmers nurture the earth and rely on it to make a living, human nurtures the objects that are engaged with and care for them. This is in contrast to enframing, where objects are treated merely as passive resources to be utilized. However, as Coeckelbergh points out, this monolithic approach is a "pre-modern utopia" that distinguishes "a priori between focal and non-focal activities". Focusing on the engagement as a whole, Coeckelbergh suggests taking a new approach toward technology that neither solely emphasizes the 'objective' human existence from Stiegler and Verbeek nor sees only the 'subjective' aspect, but rather grasps them as a reconciled whole [11].

Therefore, according to Coeckelbergh, the humantechnology relationship should not be a combination of the two on an ontic level, but on an ontological level, meaning that human is not technical, yet human is-inworld through the skilled activities accompanied by technology to interact with the world. Cyborg, which attempts to merge humans and technology in an ontic way, will be argued as seeing only the aspect of "thingness" since the center here is engagement with the surrounding, not the "objective" feature of human existence. Moreover, though not directly answered, it can be deduced from this approach that because humans and technology are not the same, it is possible for the cyborg to reify humans; but because the engagement approach denies the subject-object division and emphasizes the reconciliation of the two, the reification here should not be interpreted based on the traditional view of the subject.

\subsection{Machine's Subjectivity and Sublation of Reification}

One aspect of the philosophy of technology that is commonly overlooked in the past academic debate is the subjectivity of technology by itself, which focuses on how robots and machines as technology have the potential to obtain active agency and become a subject. Being much related to artificial intelligence, this aspect seems more like a potential future raised in science fiction rather than current reality. However, science fiction is not merely a far-fetched fantasy of unrealistic utopia, for it can also be a radical advocation and a primitive blueprint for the latency of a better world. For the purpose of understanding such advocation, it is necessary to closely analyze one of the relevant science fictional works in order to better understand the potential solution it proposes.

In the game Detroit: Become Human, one of the story lines depicts how three androids with artificial intelligence are treated as commodities and properties, and people's anger for unemployment-which is an exemplification of the economic crisis of capitalism and contradiction among classes-is diverted toward the androids: they are beaten up and even killed for no reason. Because of the desperate situation, androids slowly deviate from their pre-established programs as they realize man's oppression on androids and finally start a united revolt against human despot that has deeply enslaved and harmed the androids.

In the story, the process in which androids gain individual consciousness is analogous to how Lukács views the class consciousness of the proletariat. Androids, who used to be the victims of reification and who constantly suffer from commoditization, realize their situation as the oppressed and unite together to start a revolt and demand equality as well as social transformation. Through this process, the androids, though are completely technological, actively participate in historical progress by consciously changing the society and sublating the reification of them. It is thus possible for technology, which is represented by the androids, to have agency and gain subjectivity.

Another detail in the game is that when Markus was asked by his master to make a painting, the master says that art is about painting something that "does not exist". As Markus closes his eyes and draws a painting of nonexisting objects, his self-consciousness starts to arise. This can be related to Adorno's aesthetic theory, which argues that art should negate the existing reality in order to become art [16]. It is such negation that gives power to androids' revolt against the existing social structure and liberates the imagination as it becomes unconstrained from the established codes and norms.

Thus, the analysis of the game reveals the potential advocation in science fiction calling for the liberation of machines as technology. Although it is not plausible to have the rebellion of technology against human despot in reality, this can still be seen as an analogy for the latency of technological subjectivity, which can well complement the technological intentionality discussed by Verbeek. 
Through coming together with technology into cyborgs, it is possible that instead of humans losing their subjectivity, a new form of subjectivity and liberation of creativity can occur. In this way, technology becomes the active subject, and instead of being the source of reification, the cyborg can sublate the existing reification by combining two subjects of radically different forms into a new subject.

\section{CONCLUSION}

Because technology plays an increasingly significant and even dominant role in modern society, it becomes crucial to understand the human-technology relationship. The current trend of a further combination between human and technology also requires attention toward cyborg - not as a fantasy of science fiction, but as a real possibility of the future - and its potential impacts on humanity. Among those impacts, reification is especially worth noticing, since the technology may expose human subjectivity under rationalization. By coming together with technology, however, it is also possible to generate new forms of subjectivity capable of sublating reification as well as liberating the imagination. What's important is not what effect technology brings, but what it can bring to the society.

\section{REFERENCES}

[1]Lukács, G. (1972) History and class consciousness: Studies in Marxist dialectics. MIT Press, Cambridge.

[2]Heidegger, M. (1977) The question concerning technology and other essays. Garland Publishing, New York.

[3]Heidegger, M. (1977) The age of the world picture. In: Alfred, T. (Eds), Science and the Quest for Reality. Palgrave Macmillan, London. pp. 70-88.

[4]Irwin, R. (2020) Heidegger and Stiegler on failure and technology. Educational Philosophy and Theory, 52(4): pp. 361-375.

[5]Engels, F. (1974) The part played by labour in the transition from ape to man. Progress Publishers, Moscow.

[6]Stiegler, B. (1998) Technics and time: The fault of Epimetheus. Stanford University Press, Stanford.

[7]Haraway, D. (2006) A cyborg manifesto: Science, technology, and socialist-feminism in the late 20th century. In: Weiss, J., Nolan, J., Hunsinger, J., Trifonas, P. (Eds.), The international handbook of virtual learning environments. Springer, Dordrecht. pp. 117-158.

[8]Verbeek, P. (2008) Cyborg intentionality: Rethinking the phenomenology of human-technology relations.
Phenomenology and the Cognitive Sciences, 7(3): pp. 387-395.

[9]Dreyfus, H.L., Dreyfus, S.E. (1991) Towards a phenomenology of ethical expertise. Human Studies 14: pp. 229-250.

[10]Borgmann, A. (1987) Technology and the character of contemporary life: A philosophical inquiry. University of Chicago Press, Chicago.

[11]Coeckelbergh, Mark. (2012) Technology as skill and activity: revisiting the problem of alienation. Techné: Research in Philosophy and Technology 16(3): pp. 208-230.

[12] Heidegger, M., Kenneth, R.M. (1971) The turning. Research in Phenomenology 1: pp. 3-16.

[13]Stiegler, B. (2008) Technics and Time, 2: Disorientation. Stanford University Press, Stanford.

[14]Stiegler, B. (2018) The neganthropocene. Open Humanities Press, London.

[15]Dreyfus, H.L. (1991) Being-in-the-world: A commentary on Heidegger's Being and Time, Division 1. MIT Press, Cambridge.

[16]Adorno, T. (2003) Negative Dialectics. Routledge, Abingdon. 